\title{
Designing landscape Him Lam Phu An apartment in district 9, Ho Chi Minh city with "skyrise greenery" tendency
}

\author{
Duyen T. M. Nguyen ${ }^{1 *}$, \& Tien T. M. Duong ${ }^{2}$ \\ ${ }^{1}$ Kidohu Construction Investment Joint Stock Company, Ho Chi Minh City, Vietnam \\ ${ }^{2}$ Faculty of Environment and Natural Resources, Nong Lam University, Ho Chi Minh City, Vietnam
}

\begin{abstract}
ARTICLE INFO
Research paper

Received: September 06, 2017

Revised: November 13, 2017

Accepted: December 12, 2017

\section{Keywords}

Apartment park

Green urban space

Landscape design

Outdoor design

Skyrise greenery

\section{${ }^{*}$ Corresponding author}

Nguyen Thi My Duyen

Email: duyenntm8@gmail.com
\end{abstract}

\section{ABSTRACT}

Cited as: Nguyen, D. T. M., \& Duong, T. T. M. (2018). Designing landscape Him Lam Phu An apartment in district 9, Ho Chi Minh city with "skyrise greenery" tendency. The Journal of Agriculture and Development 17(4), 94-101.

The research carried out in the Ho Chi Minh city, from September 2016 to January 2017, aimed to green infrastructure planning, environmental restoration for apartment park, giving green space for citizens. It was conducted with some methods as: site analysis, find a function for the area, computer aided design and drafting base on main idea. We proposed two design ideas and chose the best idea for concept design, propose the instant tree list, the shrub list, the material and furniture list. Document design included: function layout plan, master plan, elevations, sections and some details of park, master perspective, detail perspectives. 


\title{
Thiết kế cảnh quan chung cư Him Lam Phú An tại Quận 9, Thành phố Hồ Chí Minh theo xu hướng "phủ xanh cao tầng"
}

\author{
Nguyễn Thị Mỹ Duyên ${ }^{1 *}$ \& Dương Thị Mỹ Tiên ${ }^{2}$ \\ ${ }^{1}$ Công Ty Cổ Phần Đầu tư Xây Dựng Kidohu, TP. Hồ Chí Minh \\ ${ }^{2}$ Khoa Môi Trường và Tài Nguyên, Trường Đại Học Nông Lâm TP. Hồ Chí Minh, TP. Hồ Chí Minh
}

THÔNG TIN BÀI BÁO

Bài báo khoa học

Ngày nhận: 06/09/2017

Ngày chỉnh sửa: $13 / 11 / 2017$

Ngày chấp nhận: 18/12/2017

\section{Từ khóa}

Công viên chung cư

Không gian xanh đô thị

Phủ xanh cao tầng

Thiết kế cảnh quan

Thiết kế không gian bên ngoài

\section{*Tác giả liên hệ}

Nguyễn Thị Mỹ Duyên

Email: duyenntm8@gmail.com

\section{TÓM TẮT}

Đề tài được tiến hành tại Thành phố Hồ Chí Minh trong thời gian từ 09/2016 đến 01/2017, với mục tiêu cải thiện cảnh quan và mang lại không gian tiện nghi, thoải mái cho người dân trong khu chung cư. Đồ án được thực hiện bằng phương pháp khảo sát và đánh giá hiện trạng khu đất, phân khu chức năng và giao thông nội bộ, thể hiện ý tưởng thiết kế chi tiết bằng việc sử dụng các phần mềm thiết kế cảnh quan và đạt kết quả như sau: phân tích và đánh giá hiện trạng khu đất thiết kế, đề xuất phương án tối ưu, đề xuất danh mục cây xanh, vật liệu, thiết bị sử dụng trong thiết kế, thuyết minh thiết kế chi tiết. Đồ án hoàn thành được các bản vẽ: mặt bằng phân khu chức năng, mặt bằng bố trí giao thông, mặt bằng tổng thể, các mặt bằng cây xanh, vật liệu, cấp thoát nước, thiết bị, bố trí chiếu sáng, mặt đứng, mặt cắt, các chi tiết của công viên và phối cảnh tổng thể cũng như phối cảnh các phân khu, các tiểu cảnh làm điểm nhấn.

\section{1. Đắt Vấn Đề}

Hiện nay, cùng với sự phát triển của nền công nghiệp hóa, hiện đại hóa, các tòa cao ốc cứ thay nhau mọc lên và "bóp nghẹt" lá phổi xanh tự nhiên. Diện tích rừng ngày càng thu hẹp, đặc biệt ở các thành phố lớn, diện tích mảng xanh trên đầu người đang ở mức báo động (Tran, 2013). Nhưng bất kì ai trong chúng ta đều không thể phủ nhận tất cả những lợi ích của các tòa nhà cao tầng mang lại trong điều kiện dân số phát triển và sự tập trung dân cư đông đúc ở các thành phố lớn. Vấn đề ở đây là làm thế nào để dung hòa sự phát triển và tính bền vững trong bối cảnh đô thị "tấc đất, tất vàng". Nắm bắt được điều đó, đồ án "Thiết kế cảnh quan chung cư Him Lam Phú An tại Quận 9, thành phố Hồ Chí Minh" sẽ là một mô hình hướng đến mục tiêu "mang thiên nhiên vào không gian sống" với mục đích tăng diện tích mảng xanh cho chung cư theo cả phương ngang và phương đứng - "phủ xanh cao tầng", đáp ứng nhu cầu vui chơi, giải trí cũng như cung cấp các tiện ích cao cấp cho người dân trong chung cư.

Dựa trên hệ thống văn bản pháp luật do Nhà nước ban hành liên quan đến công tác quy hoạch, thiết kế, xây dựng công viên cùng với quyết định phê duyệt và thẩm định thiết kế chung cư Him Lam Phú An mới nhất ngày 13/05/2016 theo văn bản 7570/SXD-TĐDA. Chung cư đang trong giai đoạn ép cọc làm móng, theo đó phần cảnh quan cũng trên đà thúc đẩy tiến độ và cần có định hướng phát triển lâu dài.

Theo Shanley (2011), thiết kế cảnh quan công viên đô thị phải đáp ứng các nhu cầu cuộc sống hiện tại, hướng đến sự bền vững trong tương lai và tạo ra cái nhìn thẩm mỹ nhưng không tách rời sinh thái. Trong điều kiện quy mô nhỏ hẹp và đan xen với các tòa nhà cao tầng, việc tận dụng tối đa diện tích dành cho mảng xanh trở thành mục tiêu hàng đầu cho cảnh quan chung cư hiện nay. Hơn nữa, tương lai của nghệ thuật kiến trúc là những ngôi nhà tràn ngập mảng xanh với không gian 
sống phủ đầy hơi thở thiên nhiên (Phua, 2016). Nắm bắt được điều này, tại chung cư Him Lam Phú An, mảng xanh sẽ được trải dài khắp công viên trên hầm đỗ xe, phủ xanh tường cao theo hệ khung chậu HPDE, và tận dụng tầng thượng phát triển vườn rau trên mái phục vụ nhà hàng tại chỗ theo hướng nông nghiệp đô thị (Nguyen, 2011).

Ngoài những lý thuyết đút kết được, các nghiên cứu về những công trình thực tế trong và ngoài nước cũng mang lại nhiều kinh nghiệm như: thiết kế công viên trên tầng hầm từ công viên chung cư Him Lam Chợ Lớn (Thành phố Hồ Chí Minh), bố trí không gian xanh giữa các tòa nhà từ chung cư InterIace (Singapore), chung cư Downtown Phuket (Thái Lan), chung cư Summer (Thái Lan), trồng rau trên sân thượng từ nhà hàng Club Pastry $(M \tilde{y}), \ldots$ Đây sẽ là nền tảng để chung cư Him Lam Phú An trở thành dấu gạch nối cho xu hướng "Phủ xanh cao tầng" từ Singapore nói riêng và Thế giới nói chung, đánh dấu một bước phát triển cho kiến trúc hiện đại Việt Nam.

\section{Vật Liệu và Phương Pháp Nghiên Cứu}

Phương pháp khảo sát thực địa: Khảo sát điều kiện tự nhiên bằng cách chụp ảnh công trình từ nhiều hướng, khảo sát địa hình bằng phương pháp quan sát dựa trên thông tin dự án, khảo sát giao thông và vị trí khu đất bằng cách quan sát và tham khảo bản đồ, khảo sát thực vật bằng cách chụp hình, định danh thực vật hiện trạng, khảo sát công trình liên quan xung quanh khu đất thiết kế, tham khảo ý kiến chủ đầu tư. Tổng hợp thông tin và phân tích, đánh giá hiện trạng.

Phương pháp thu thập thông tin: tham khảo tài liệu liên quan về điều kiện tự nhiên khu dất (khí hậu, hướng gió, hướng nắng...). Tham khảo tài liệu về các loài cây được trồng và hạn chế trồng ở địa phương. Tham khảo các công trình tương tự về các giải pháp cảnh quan tương đồng về điều kiện thông qua các tạp chí kiến trúc cảnh quan và khảo sát thực tế (chung cư Him Lam Chợ Lớn). Riêng phân tích hướng nắng và bóng đổ được thực hiện bằng phần mềm Autodesk Ecotect Analysis 2011, dựa trên mô hình 3D mô phỏng công trình kết hợp dữ liệu thời tiết thành phố Hồ Chí Minh.

Phương pháp thiết kế: phân tích thiết kế, tìm ý tưởng, và thể hiện bằng các phần mềm đồ họa chuyên ngành như: AutoCad 2014, Sketchup 2015, Lumion 5, Photoshop CC,...
Đúc kết từ những thông tin thu thập, xác định phương án thiết kế theo tiêu chí "xanh, sạch, đẹp", phù hợp với nhu cầu sử dụng của người dân cũng như yêu cầu của chủ đầu tư. Hơn hết, công trình còn phải đảm bảo nét riêng làm nền tảng cho bước đầu đưa xu hướng phủ xanh cao tầng trở nên phổ biến ở Việt Nam.

\section{Kết Quả và Thảo Luận}

Tập đoàn Him Lam Land đã bắt tay vào thực hiện dự án chung cư Him Lam Phú An, với tổng diện tích 1,8 ha, trong đó diện tích cho mảng xanh là 0,87 ha. Nhờ vị trí đắc địa và theo đối tượng hưởng dụng, chung cư được đầu tư như một căn hộ cao cấp, tiện nghi và năng động. Nhưng bên cạnh những thuận lợi, thì Phú An vẫn còn một số vấn đề bất cập cần có giải pháp hợp lý.

Chung cư Him Lam Phú An tọa lạc tại phường Phước Long, Quận 9, Tp Hồ Chí Minh, tại cửa ngõ Đông Sài Gòn, nằm trong vùng đô thị đang phát triển. Tại nơi đây, chung cư chịu ảnh hưởng của đảo nhiệt đô thị, nhiệt độ cục bộ cao hơn ở vùng ngoại ô hay nông thôn. Bên cạnh đó, chung cư còn được thiết kế với 4 block nhà đối diện nhau tạo thành dạng ống, chính vì thế công viên trung tâm chịu ảnh hưởng trực tiếp của hiệu ứng gió nhà cao tầng, tức là gió ở đây sẽ mạnh hơn do cơ chế của khí động học (Pham, 2012), điều này ảnh hưởng rất lớn đến vấn đề bố trí mảng xanh cho chung cư.

Thêm vào đó là những tác động từ điều kiện tự nhiên, theo khảo sát hiện trạng và kết quả mô hình hóa qua phần mềm phân tích năng lượng Autodesk Ecotect Analysis, chung cư có công viên trung tâm chỉ nhận được khoảng 4 giờ chiếu sáng mỗi ngày nên chủng loại cây trồng khá hạn chế.

Sau quá trình thu thập, xử lý các tác động đến cảnh quan chung cư, nhận thấy công trình được ưu đãi về vị trí địa lí chiến lược, điều kiện tự nhiên thích hợp với nhiều chủng loại cây trồng, và được đầu tư đa dạng hạng mục, khu vực thiết kế bằng phẳng, rõ ràng (Hình 1). Tuy nhiên, công viên trung tâm nằm ngay trên hầm đỗ xe, và chung cư phải chịu ảnh hưởng của hiệu ứng gió nhà cao tầng, cũng như sự chênh lệch thời gian, cường độ chiếu sáng đến các khu vực của công trình (Hình 2 và 3 ). Chính vì thế, để đáp ứng những tiêu chí đề ra chung cư Him Lam Phú An được định hướng phát triển theo hướng "phủ xanh cao tầng" cả phương ngang lẫn phương đứng, với công viên trung tâm trên tầng hầm, vành đai cây xanh, 
tường xanh và vườn rau trên mái.

Theo đó, cảnh quan mặt đất được phân khu theo chuỗi tiện ích bao gồm cổng chào, lối vào, vành đai cây xanh, hồ cảnh quan và bảng tên, vườn nghỉ, sân chơi trẻ em, sân tập thể dục thể thao, khu nướng ngoài trời, và hồ bơi (Hình 4).

Chung cư Him Lam Phú An định hướng thiết kế theo phong cách hiện đại, tạo không gian sống năng động và tiện nghi. Lấy ý tưởng từ vi mạch điện tử, mong muốn tạo ra sự kết hợp giữa những thành quả của công nghệ với thẩm mỹ cảnh quan, những thứ tưởng chừng như khô khan cũng có thể tạo nên một tiếng nói riêng khi người ta biết cảm nhận nó. Sự ra đời của vi mạch điện tử là bước ngoặt cho cuộc Cách mạng khoa học kỹ thuật. Chính vì thế, ý tưởng này còn theo đúng chủ đề của chung cư, định hướng phát triển theo hướng năng động, dân cư chủ yếu là các gia đình 1-2 thế hệ.

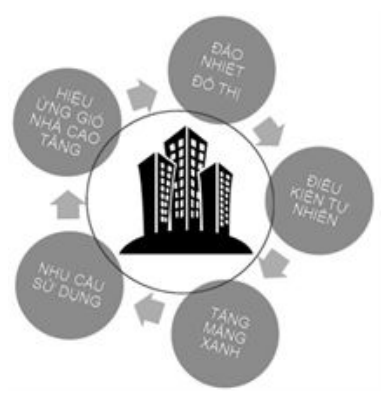

Hình 1. Các ảnh hưởng đến thiết kế cảnh quan chung cư Him Lam Phú An.

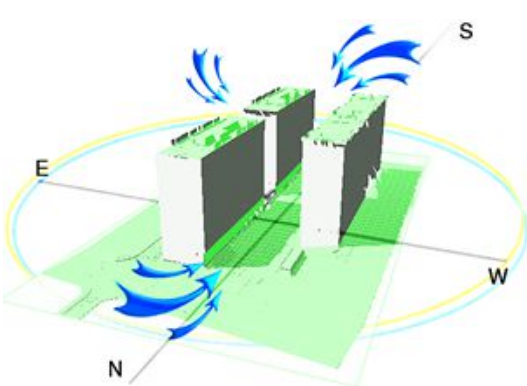

Hình 2. Họa đồ thể hiện hướng gió tác động đến chung cư.

Cảnh quan chung cư Phú An được thiết kế theo phong cách đơn giản và hiện đại. Những đường nét khỏe khoắn của bồn cây và vật liệu nền tạo mối liên kết xuyên suốt từ cổng chào đầu đến cuối công trình, từ khu động đến khu tĩnh, từ khu công năng này đến khu công năng khác. Đi

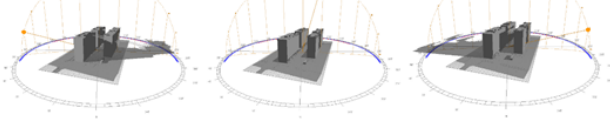

Hình 3. Họa đồ thể hiện hướng nắng và bóng đổ lúc 7-13-17 giờ.

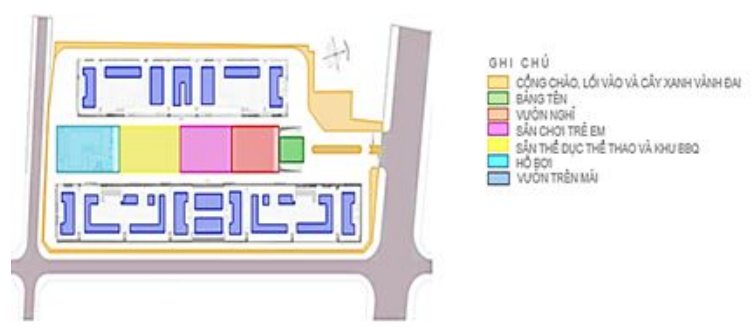

Hình 4. Phân khu chức năng khu vực thiết kế.

từ ngoài vào, sau khi được chào đón bằng cổng chào, thì tiểu cảnh bảng tên chung cư ở giữa sẽ hướng người vào đến công viên với trung tâm, cũng như hướng người lái xe đỗ xe ở tầng hầm ngay bên dưới. Công viên bắt đầu bởi tiểu cảnh bảng tên chung cư, sau đó là khu vườn nghỉ chủ yếu dành cho người lớn tuổi, tiếp theo là khu vui chơi trẻ em, đây cũng được xem là khu trung tâm. Tiếp nối với sự náo động là khu dành cho các hoạt động vui chơi, thể dục thể thao. Cuối cùng là khu phức hợp nướng ngoài trời và hồ bơi, là nơi lý tưởng cho những buổi tiệc (Bảng 1 và Hình 5).

Bảng 1. Bảng cơ cấu sử dụng đất của cảnh quan chung cư

\begin{tabular}{cccc}
\hline STT & Khu vực thiết kế & $\begin{array}{c}\text { Diện tích } \\
\left(\mathrm{m}^{2}\right)\end{array}$ & $\begin{array}{c}\text { Tỉ lệ } \\
(\%)\end{array}$ \\
\hline 1 & Tổng cảnh quan & 6.000 & 69 \\
2 & mặt đất & & \\
3 & Tường xanh & 200 & 2 \\
Tổng diện tích thiết kế & 8.700 & 100 \\
\hline
\end{tabular}

Phần cảnh quan chung cư được chia làm 4 phần:

- Khu cổng chào và vành đai cây xanh (Hình 6): Phần cổng chào và vành đai cây xanh có diện tích $3.000 \mathrm{~m} 2$. Cảnh quan cổng chào là vùng đệm giữa đường phố và lối vào chung cư nên là sự kết hợp giữa quy cách và phá cách, giữa tiếp nối và điểm nhấn. Chung cư không sử dụng hết phần đất theo chỉ giới xây dựng mà trích từ quỹ đất 


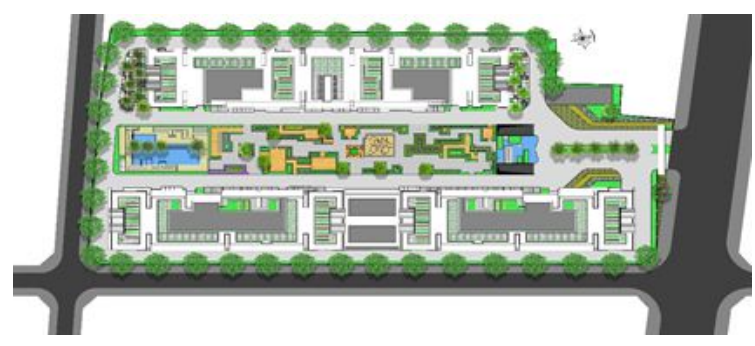

Hình 5. Mặt bằng tổng thể.

làm cảnh quan bên ngoài với tiểu cảnh đồi bên cây Chiếc (Barringtonia racemosa) gợi nhớ đến cái tên Rạch Chiếc gắn bó qua bao thế hệ nơi đây (Nguyen, 2015). Tiếp tục đi vào trong, những đường nét thẳng tắp từ cổng chào và mở rộng ra phía sau tạo cảm giác không gian mở ra như một lời chào đón. Block nhà $\mathrm{C}$ và $\mathrm{D}$ được tăng cường mảng xanh cho hoạt động dạo mát và nghỉ ngơi. Sử dụng những tán cây Cọ dầu (Elaeis guineensis) xòe tròn tương phản với hình khối dạng phương đình của bồn cây kết hợp với các khóm cây bụi thường xanh và bền như Bạch trinh biển (Hymenocallis littoralis), Ô rô gân vàng (Eranthemum reticulatum) trên nền gạch phối kết đậm nhạt theo ô lưới 90 độ. Sự nhấn mạnh được thể hiện bằng cây Bàng đài loan lá cẩm thạch (Terminalia mantaly) trên nền cây bụi phủ xanh. Xung quanh chung cư được bao bọc bởi vành đai cây Long não (Cinnamomum camphora) trên thảm cỏ lá gừng vừa làm mát tường bê tông vừa phù hợp với tiêu chuẩn cây xanh đô thị, giúp phân chia ranh giới bên ngoài và tăng mảng xanh bên trong.

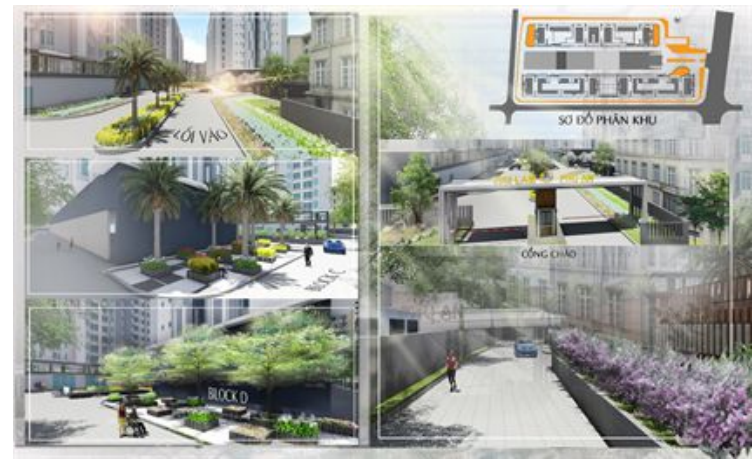

Hình 6. Phối cảnh cổng chào và vành đai cây xanh.

- Khu công viên trung tâm gồm các phân khu: $\diamond$ Hồ cảnh quan và bảng tên (Hình 7):

Nước là một trong những yếu tố quan trọng thu hút thị giác (Han, 1999). Sử dụng hồ cảnh quan chảy tràn theo các bậc đá giật cấp, xen lẫn đá trang trí, trụ phun nước, cùng đèn led âm nước, làm dịu đi cảm giác nóng bức từ nhựa đường và không bị lóa sáng khi vào công viên cũng như an toàn lái xe xuống hầm đỗ xe. Bảng tên Phú An và logo Him Lam nổi bật tạo sức hút mạnh mẽ so với cảnh quan tươi mát xung quanh.

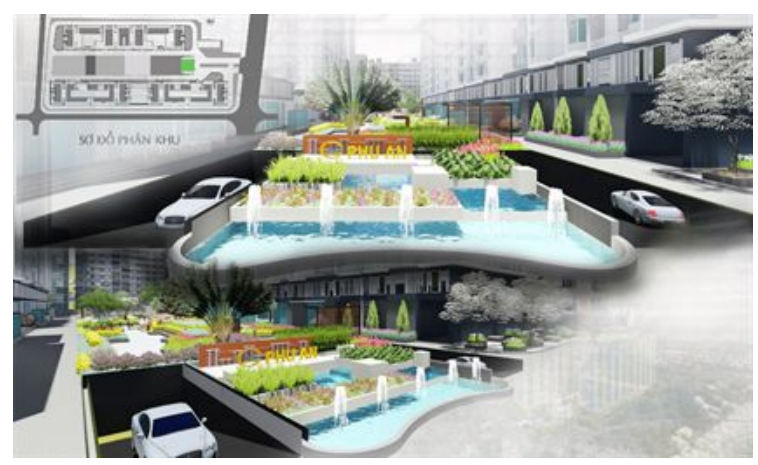

Hình 7. Phối cảnh hồ cảnh quan và bảng tên.

Thực vật khu này cũng đa dạng phân tầng từ những loài thủy sinh, ưa ẩm đến giới hạn sống rộng, từ màu làm nền đến màu điểm nhấn, từ thấp, trung đến cao tạo nên tường cây ngăn với phần công viên cho cảm giác an toàn và riêng tư phù hợp với công năng của khu vườn nghỉ phía sau.

$\diamond$ Vườn nghỉ (Hình 8): Vào ban ngày chung cư chủ yếu phục vụ cho người lớn tuổi, người khuyết tật và trẻ em. Khu vườn nghỉ được bố trí khoảng $10 \mathrm{~m}$ ghế liền khối, với hai mái che, cùng với những ram dốc, lối đi theo tiêu chuẩn dành cho người khuyết tật. Hệ thống cây xanh đáp ứng tốt nhất nhu cầu thưởng ngoạn và mang lại không khí tươi mát. Lá dứa (Pandanus amaryllifolius) là cây chủ đạo cho khu vực này, nhờ màu xanh mát, hình dáng đẹp và mùi hương nhẹ dịu, dễ chịu, kết hợp với Bạch trinh biển (Hymenocallis littoralis) và Sẹ đỏ (Costus woodsonii) dể tạo ra sự tương phản xanh - đỏ - xanh qua ba bậc.

$\diamond$ Khu vui chơi trẻ em (Hình 9): Đây là khu trung tâm của công viên bởi nhu cầu sử dụng và điểm nhấn hình khối trong tổng thể thiết kế. Thiết kế trò chơi cho trẻ theo ý tưởng giải mã mê cung, tạo sự mới lạ hơn các trò chơi có sã̃n có trên thị trường. Đối với thiết kế này, đồ án mong muốn hình thành tính khám phá, logic trong trẻ từ nhỏ. Hiểu được tính hiếu động của trẻ, nên vấn đề an toàn được đặt lên hàng đầu. Toàn bộ sân chơi được trải cát mịn, trò chơi làm bằng gỗ, nhựa và lưới trên nền sân cát giúp tiết kiệm một phần 


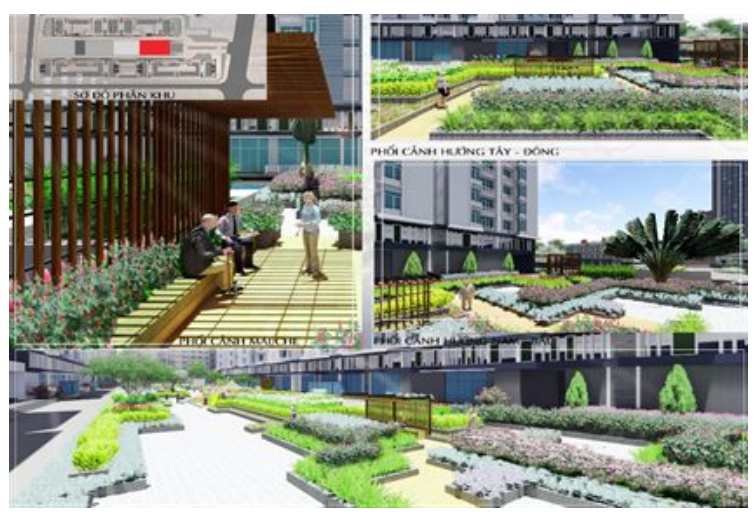

Hình 8. Phối cảnh vườn nghỉ.

chi phí. Bên cạnh đó, kết hơp với sân EPDM theo đường nét chủ đề của chung cư giúp làm đa dạng môi trường vui chơi cho trẻ. Xung quanh sân chơi là những dãy ghế dài dựa lưng thành bồn cây cho phụ huynh quan sát trẻ. Những bồn cây ôm theo sân chơi chính còn có chức năng giới hạn không gian, hạn chế trẻ chạy ra ngoài đường.

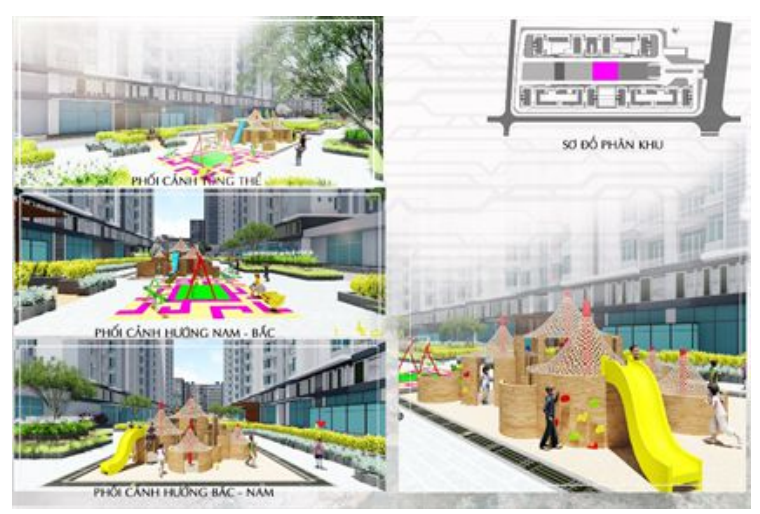

Hình 9. Phối cảnh khu vui chơi trẻ em.

$\diamond$ Khu thể dục thể thao (Hình 10): Tất cả các sân được mở theo chiều dài để thuận tiện cho các hoạt động thể thao và nằm gọn giữa những bồn cây và mái che, giúp tránh say nắng, mất sức cho người vận động nhiều. Sân cầu lông được lắp đặt theo chiều ngang để tránh chói nắng và mất an toàn khi cầu rơi ra ngoài đường giao thông. Sân tiếp theo lắp đặt thêm các thiết bị, dụng cụ thể dục thể thao ngoài trời phục vụ cho nhu cầu của người luyện tập. Các sân không chỉ hướng đến giới trẻ ưa vận động mà còn chú ý đến cả người già và người khuyết tật, các lối tiếp cận đều tạo độ dốc để tiện việc di chuyển. Sân còn lại nằm đối diện và tách biệt với sân đôi, không gian tĩnh hơn với một vài máy tập còn lại là diện tích cho các bài tập và đường chạy. Sử dụng các loại cây có dược tính như Cúc mốc (Crossostephium chinense), Bạc hà (Mentha piperita) kết hợp với cây cảnh trang trí.

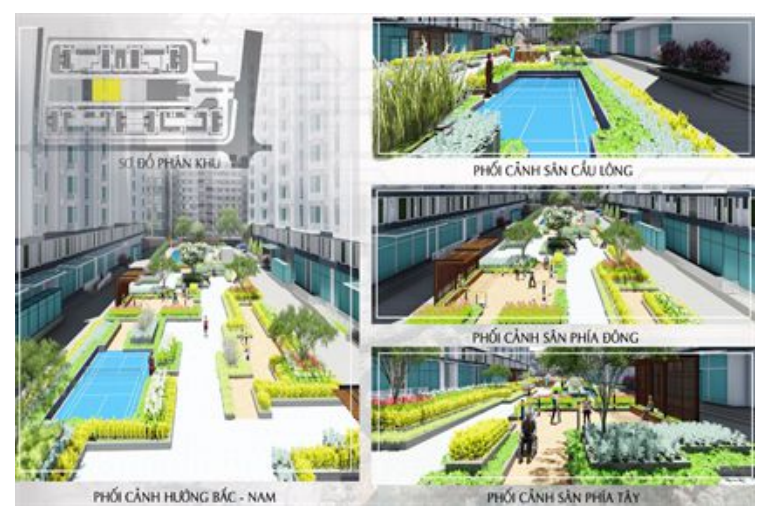

Hình 10. Phối cảnh khu thể dục thể thao.

$\diamond$ Khu $\mathrm{BBQ}$ - nướng ngoài trời (Hình 11): Phía trước khu nướng ngoài trời là bồn cây lớn, vừa là điểm nhấn vừa có các dụng ngăn cách khu. Khu này lắp đặt lò nướng, tủ gia vị, bồn rửa và ghế dài để đáp ứng tiện nghi cho người sử dụng. Trồng kết hợp cây có thể dùng làm thực phẩm như cây Lá lốt (Macropiper sarmentosa), Hương thảo (Rosmarinus officinalis), đinh lăng (Polyscias fruticosa) tạo nét đặc trưng cho khu vực này.

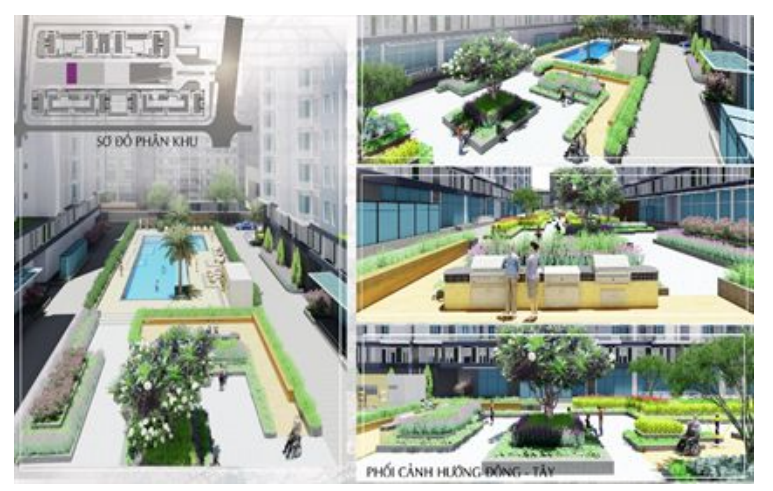

Hình 11. Phối cảnh khu nướng ngoài trời.

$\diamond$ Hồ bơi (Hình 12): Hồ trẻ em diện tích $33 \mathrm{~m}^{2}$ hồ cho người lớn khổ $218 \mathrm{~m}^{2}$. Tiếp nối theo phong cách và họa tiết của các khu trước, thay cho các bồn cây thì họa tiết khu này được cách điệu bằng vật liệu khác hoặc sàn hoặc mái che. Được bố trí thêm những bồn cây Cọ dầu để phân chia không gian giữa 2 hồ, nhờ đặc tính ít rụng lá, thân dạng độc trụ làm không gian thông thoáng. Bố trí thêm 
vòi tắm ngoài trời để giữ vệ sinh hồ cũng như bảo vệ cơ thể trước nhiều tác nhân gây bệnh (Hlavsa, 2016), quầy phục vụ, phòng thay đồ, mái che, ghế nằm, ghế bành theo phong cách tối giản, hiện đại nhưng mang lại một không gian tươi mát và tiện nghi. Xung quanh khu hồ bơi còn được bao bọc bởi tường cây hạn chế tầm nhìn tạo không gian riêng tư và cảm giác an toàn cho người sử dụng.

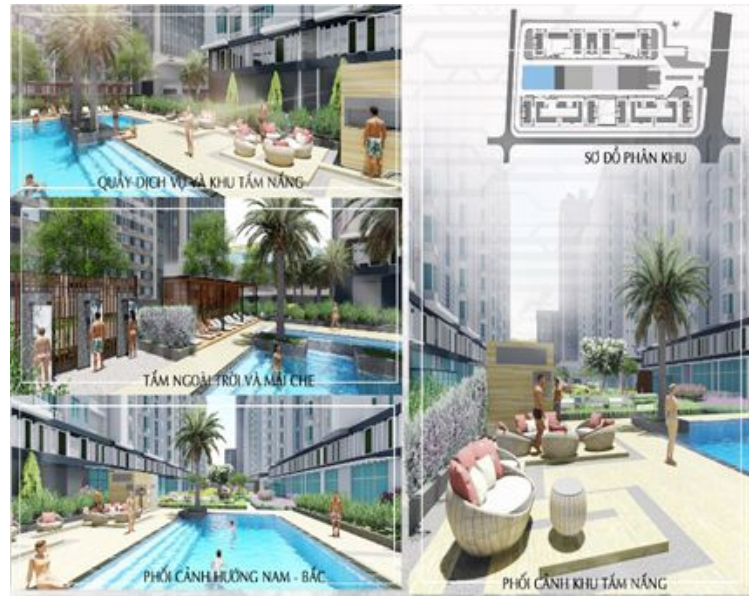

Hình 12. Phối cảnh khu hồ bơi.

- Khu vườn trên mái (Hình 13): Hiện nay, diện tích đất đang bị thu hẹp kèm theo vấn đề an toàn đang ở mức báo động thì việc trồng rau trên mái là một giải pháp hữu hiệu và thu hút sự quan tâm của nhiều người (Huynh, 2016). Vì thế, tầng thượng của chung cư Him Lam Phú An được dùng làm vườn rau phục vụ cho nhà hàng tại chỗ, vừa mang lại hiệu quả kinh tế vừa đảm bảo an toàn cho điều kiện gió lớn ở đây. Các loại rau được trồng xen kẽ, theo mùa, theo nhu cầu sử dụng và được phối kết như các loại cây bụi trang trí, kết hợp những giàn dây leo che mát và có thể thu hoạch sản phẩm. Tuy nhiên, cần có những kế hoạch phối kết cây trồng có khả năng xua đuổi côn trùng, sâu hại, hay thu hút thiên địch,... (Nguyen, 2005). Sử dụng những khay trồng rau thông minh đang được bán trên thị trường kết hợp các thanh gỗ pallet đã qua sử dụng để tạo khung, kệ trang trí cũng như làm nên phong cách nhẹ nhàng, gần gũi hơn cho vườn rau. Ngoài vấn đề thẩm mỹ, thì tính thực tế cũng không thể thiếu, rau màu thường là những loại ngắn ngày cần chăm sóc thường xuyên vì thế cần phải đảm bảo lối tiếp cận thu hoạch cũng như tham quan dễ dàng, chiếu sáng cũng phải tuân theo nguyên tắc bố trí đèn sân vườn và không ảnh hưởng đến sự sinh trưởng của rau màu, quan trọng hơn là giải quyết vấn đề thoát nước thừa hay nước mưa chảy tràn. Ngoài ra, đây còn là nơi áp dụng, thí điểm các kỹ thuật, loại hình mới, giúp người dân gần hơn với các công nghệ mới trong chương trình nông nghiệp hóa đô thị. Như các hình thức của mô hình thủy canh vẫn đang được ưa chuộng vì tính hiệu quả và thẩm mỹ của chúng mang lại.

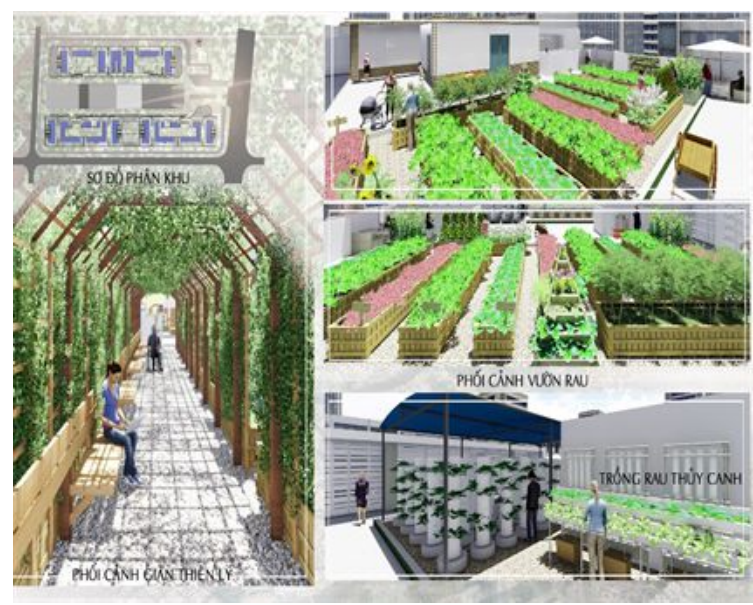

Hình 13. Phối cảnh khu vườn trên mái.

- Khu tường xanh (Hình 14): Được sử dụng để làm tăng mảng xanh nên yêu cầu bố trí đơn giản và bền, ít bảo dưỡng. Tường xanh là một phần quan trọng để tạo ra hiệu ứng phủ xanh cao tầng, kết nối cảnh quan mặt đất với cảnh quan tầng thượng. Hệ thống tường xanh của chung cư đã được thiết kế khung cố định, bắt đầu ở cao độ 4,95 m so với mặt đất (tầng 2 ). Hệ thống tường xanh gồm 2 loại, loại 1 kích thước $1.200 \times 1.800$ mm, loại 2 có kích thước $600 \times 1.800 \mathrm{~mm}$. Theo đó, lấy ý tưởng thiết kế từ hình ảnh cầu vồng, nhấn mạnh màu sắc bằng cách trồng đồng nhất một loại thực vật trên 1 khung lớn và vẫn giữ màu xanh chủ đạo bằng các khung nhỏ. Mỗi tường xanh là một màu, cứ như thế tạo thành một dải màu chạy dài theo các tòa nhà chung cư.

Sử dụng chậu nhựa HPDE theo quy cách với hệ thống khung và tưới nhỏ giọt kèm theo. Mô hình này có nhiều ưu điểm như dễ thi công lắp đặt, không ảnh hưởng nhiều đến tường, lượng chất trồng phù hợp, độ bền cao và ít bảo dưỡng. Một số loài điển hình như: dương xỉ (Nephrolepis biserrata), trầu bà vàng (Philodendron erubescens), bảy sắc cầu vồng (Tradescantia spathacea), tróc bạc (Syngonium 'White Butterfly'), tuyết sơn phi hồng (Leucophyllum frutescens),... 


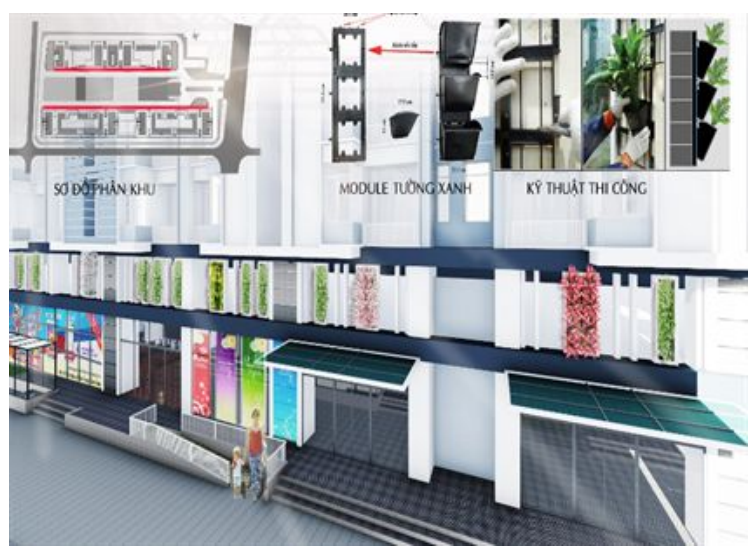

Hình 14. Phối cảnh và hệ thống tường xanh.

\section{Kết Luận và Đề Nghị}

Hiểu được mong muốn của dân cư trong các chung cư về những diện tích bổ sung để mở rộng không gian sống, cảnh quan khu chung cư Him Lam Phú An là mô hình phát triển dựa trên tiêu chí tận dụng tối đa diện tích để tăng cường mảnh xanh theo cả phương ngang, lẫn phương đứng thông qua các hạng mục tạo vành đai xanh xung quanh công trình, phủ xanh tường tạo kết nối giữa công viên trung tâm với vườn trên mái. Chung cư như trở thành một khối xanh đa chiều mang tính toàn diện hơn mảng xanh đơn thuần tạo ra một môi trường xanh - sạch - đẹp và tiện nghi cho người sử dụng với phong cách hiện đại, tinh tế và năng động. Mô hình phủ xanh cao tầng Him Lam Phú An hứa hẹn sẽ là hình ảnh độc đáo giữa thành phố, góp phần khuyến khích xu hướng mang thiên nhiên vào cuộc sống hàng ngày cũng như giáo dục cộng đồng về ý thức môi trường.

Nghiên cứu chỉ dừng lại ở ý tưởng không gian, cần được hoàn thiện hơn về các hệ thống kỹ thuật hạ tầng. Chú ý công tác bảo dưỡng cảnh quan theo định kì để duy trì hiệu quả thiết kế lâu dài.

\section{Tài Liệu Tham Khảo (References)}

Han, N. T. (1999). Landscape architecture. Ha Noi, Vietnam: Construction Publishing House.

Hlavsa, M. (2016). Pool party poopers: CDC warns of parasitic infection, toxic gas. Retrieved May 19, 2017, from http://edition.cnn.com/cryptosporidiumchlorine-gas-pool-cdc/index.html.

Huynh, H. X. (2016). Solutions for cooling private houses in the hot weather season. Retrieved March 3, 2014, from http://trongraunhavuon.vn/trong-rauxanh-tren-san-thuong-giai-phap-ha-nhiet-cho-nhapho-mua-nang-nong/.

Nguyen, L. T. (2015). Sai Gon: Land and People. Ho Chi Minh, Vietnam: The Ho Chi Minh City General Publishing House.

Nguyen, N. D. (2011). Urban and peri-urban agriculture. Retrieved August 2, 2011, from https://ashui.com/quy-hoach/5200-nong-nghiepven-do-thi.html.

Nguyen, N. T. (2005). Measures for preventing and eliminating pests and diseases of vegetables. Retrieved December 7, 2015, from http://nongnghiep1.com/bienphap-tong-hop-phong-tru-sau-benh-hai-rau/.

Pham, D. N. (2012). Tornado prevention for high buildings should be made into law. Retrieved July 30, 2016, from https://www.tienphong.vn/xa-hoi/can-dua-viecchong-loc-xoay-cho-cao-oc-vao-luat-1033144.tpo.

Phua, P. (2016). Green tendency in world architecture. Retrieved October 7, 2016, from https://www.tapchikientruc.com.vn/chuyen-muc/xuhuong-xanh-hoa-cua-kien-truc-gioi.html.

Shanley, K. (2011). Urban park landscape. Hong Kong, Hong Kong: Design Media Publishing.

Tran, M. V. (2013). Effects of evergreen plant on environment and climate. Retrieved May 12, 2015, from http://www.baomoi.com/tphcm-dien-tichcay-xanh-chi-dat-10m-nguoi/c/11002531.epi. 